Shoemaker's "Materia Medica and Therapeutics." Philadel.Phia, Feb. 20, 1907.

To the Editor:-While thanking you for your favorable notice of my "Materia Medica and Therapeutics," sixth edition, I would regard it as only just to me that a misconception on th part of the reviewer should be corrected, and I ask you to publish this explanation in an early issue of THE JoUrnaL. Unlike other text-books, my work is based on both the United States Pharmacopeia and the British Pharmacopeia, so that it can be used in all parts of the world where these two standards are in force. Unfortunately, the committee of revision did not see its way clear to adopt the English titles of some drugs, like carbolic acid and sulphonal, but authorized "phenol," "hexamethylenamine," etc., instead. A careful examination of my work will show that these drugs are described under both of their official titles, with full explanation given under each heading. Unofficial new drugs, of course, are described under their proper names (and also trade names) with their chemical formulas appended. Your reviewer's statement that "Unofficial preparations . . . unfortunately are described under proprietary or trade names, regardless of the fact that some of them have been admitted to the Pharmacopeia under other names," is both contradictory and incorrect. Of course, a preparation can not be unofficial and, at the same time, be included in the Pharmacopeia, while to imply that trade names are used without giving the Pharmacopeial equivalents is stating the reverse of the truth. No confusion, for instance, can arise from the discussion of "carbolic acid" among the acids according to the British Pharmacopeia, when it is accompanied by the U. S. P. title of "Phenol hydratum," and there is also a cross reference under "Phenol" in its place.

JoHN V. SHOEMAKeR.

\section{The Etiology of Rheumatism in Children.}

MAYWOOD, ILL., Feb. 16, 1907.

To the Editor:-Reading the theories, new and old, of the etiology of rheumatism in children, in THE JoURNaL of recent date, reminds me of a patient under $m y$ care two years ago. It was a typical case of croupous pneumonia in a boy of 7 . The erisis was passed on the fifth day. The second day following he developed rheumatic fever with swollen and extremely painful ankle and knee joints on the right side, which several days later shifted to the left side. Under the usual treatment he made a good recovery. This suggests the probability of the canse of the rheumatism as being Diplococcus pneumonice infection, and offers a field for research.

O. E. Matter, M.D.

\section{Book Notices}

A Text-Book of Diseases of Women. By J. C. Webster, B.A. M.D.. F.R.C.P.E., F.R.S.E. Professor of obstetrics and Gynecology in Rusi Medical College, in affilation with the University of Chicago. With 372 Illustrations and 10 Colored Plates. Cloth. Pp.

It is a pleasure to review this excellent addition to American text-books on gynecology. The author has succeeded in adhering to the guiding principles which he formulates: To give prominence to the scientific basis of each subject under consideration, including the results of research in anatomy, histology, embryology, comparative anatomy, pathology and bacteriology; to study clinical phenomena in their widest re. lationships; to insist on caution in the adoption of new and insufficiently tried therapeutic measures and to emphasize measures proved by his own experience. As a general basis for the study of pathology and treatment he has necessarily devoted about one-seventh of the book to a full and very carefully prepared description of the anatomy of the female organs. This subject, well elucidated by 82 carefully selected illustrations, is presented in a chapter that gives a picture of the gross and microscopic structure, the development and the physiology that can hardly be excelled. Likewise the short chapter of ten pages on the genital tract in relation to microorganisms gives a well presented resume of the bacteriolgy of the genital tract in various conditions and the relations of micro-organisms to pelvic disease. The chapter on puberty and menstruation, including the diseases of menstruation, is as satisfactory a presentation of this difficult subject as is perhaps possible in the present unsettled condition of our knowledge. The author's treatment of neuroses in relation to pelvic disease in women, including hysteria and neurasthenia, together with his advice concerning the surgical treatment of chronic ovaritis and cystic degeneration of the ovaries in a later ehapter will, perhaps, from some receive more criticism than anything else in the book. Although Webster insists that operative treatment of neurasthenia should not be placed in the forefront of therapeutic measures, yet the conclusion that marked neuroses may be associated with cystic degeneration of the ovaries, with slight or absent pelvic symptoms because of reflex nervous disturbances from ovarian tension, or because of disturbance of ovarian secretion, and the statement that ovarian resection or removal has been frequently followed by a cure, will arouse opposition. Professor Webster, however, is well trained in modern pathology, and when he enunciates his well-known views on this subject he probably finds himself still able to defend them as he has done in the past. The chapters on case taking and physical exercise and that on minor therapeutic measures are similar to those in other works. Local massage is condemned. Pessaries are described and in certain conditions advocated, but evidently without much predilection for them. Surgical technic is described in great detail and is well illustrated. Only a most carefully trained operator with a highly sensitive "surgical conscience" could have produced this excellent description of abdominal and vaginal operations. Considerable attention is given to the technic and the advantages of local anesthesia.

The description of the various pathologic conditions found in the pelvic organs and their treatment is presented with as great degree of detail and completeness as is possible, considering the limits imposed by the size of the book. It is impracticable as well as unnecessary in a review to attempt to give the views of the author on the different gynecologic problems of the present time. To some of these problems Webster has made original contributions. Others are discussed from a point of view of one familiar with all the literature of the day, and who himself has tested many of the therapeutic measures that have been advocated. The result is a modern presentation of gynecology, differing, perhaps, not so much from that of others, but very satisfying to the reader because of the confidence he intuitively feels in the masterly handling of all the subjects. It is this great excellence combined with the unusual thoroughness of the introductory chapters that will secure for this work a wide and admiring circle of readers.

Therapeutische Technif fuer die agrztliche praxis. By J. Schwalbe Erster Halbband. Mit 390 Abbildungen. Paper. Pp. 352. Leipsle: Verlag von Georg Thieme, 1906.

Therapeutics is acknowledged to be the first and most important task of the physician, and its recent developments have been largely in directions which demand a degree of technical knowledge and manual skill far in advance of that required when the physician's task was limited to the composition and writing of a compatible prescription. Many of the recent advances are, to be sure, in the domain of specialists, but their importance is such that it is almost imperative that the general practitioner should be well acquainted with them if he is to do the best for his patients and not lose them unnecessarily to the specialist.

The book before us is an attempt to furnish practicing physicians with an answer to the question what to do and how to do it. It is brought out under the general editorship of $\mathrm{J}$. Schwalbe, with the collaboration of a number of eminent German clinicians. It is devoted to the technic of therapeutics and gives in detail the various procedures with the method of application and indications for their use, and in certain cases a comparison of various methods with a statement of their relative advantages and contraindications. The subjects treated in Vol. 1 are: Massage, gymnastics, the technic of mechanical hydrotherapy and thermotherapy, radiotherapy, preparation and application of medicines, surgical technic, and 